\title{
Do mito à realidade e à utopia: Agostino Codazzi, precursor da geografia moderna, no projeto do Atlas da Venezuela (sec. XIX)
}

\author{
From myth to reality and utopia: \\ Agostino Codazzi, precursor of modern geography, the \\ design of the Atlas of Venezuela (Nineteenth Century)
}

\author{
Maria Carmela D'Angelo* \\ (Tradução de Leonardo Conedera e \\ Núncia Santoro de Constantino)
}

\begin{abstract}
Resumo: O italiano Giovanni Battista Agostino Codazzi (1793-1859), mais conhecido na América Latina como Agustín Codazzi, militar, cientista, geógrafo e cartógrafo italiano, encontrou-se entre os primeiros exploradores que, na primeira metade do século XIX, observou a América do Sul com espírito científico, particularmente o território entre a Venezuela, Colômbia e Equador, retirando-lhe da áurea mitológica que até então o cercava. Um dos resultados mais tangíveis dessas observações foi a definição das fronteiras entre os três países, além da redação de uma cartografia apreciada à época pelos cientistas de toda a Europa, que contribuiu para criar os fundamentos da geografia moderna, também em virtude da aproximação multidisciplinar perseguida por essa geografia moderna.
\end{abstract}

Palavras-chave: Agostino Codazzi. América do Sul (Venezuela, Colômbia, Equador). Geografia moderna.

Abstract: The Italian born Giovanni Battista Agostino Codazzi 1793-1859 (better known in Latin-America as Agustín Codazzi) soldier, scientist, geographer and cartographer, was one of the first European in exploring, during the first half of the XIX century, South America, especially the area between Venezuela, Columbia and Ecuador, according a new scientific approach, keeping out this territory from the mythological aura that always involved it. One of the most relevant and touchable result was the definition of the borderline between the three countries over quoted, together with the redaction of a rich cartography highly regarded since that time

* Professora do Ministério do Exterior italiano, atualmente em serviço na Universidade de Groningen (Holanda), na Faculdade de Letras, Departamento de Italiano. 
from the scientists and specialists in all Europe. His works gave a large contribution for creating the basis of the modern geography, thanks to the multidisciplinary approach pursued in his researches.

Keywords: Agostino Codazzi. South America (Venezuela Colombia Ecuador). Modern geography.

\section{Introdução}

Por muitos considerada leviana e privada de qualquer fundamento, a ideia de "buscar o Levante pelo Poente", segundo a expressão que sintetizou o senso de audácia de Cristóvão Colombo, não nasceu por casualidade ou por puro espírito de aventura. Pelo contrário, surgiu como direta e lógica consequência de uma longa série de revisões científicas e técnicas, produzidas no transcurso dos séculos. Entre outros, um dos mais estimados cientistas do século XIX, Alexander von Humboldt (1769-1859) demonstrou, através da análise de documentos originais por ele mesmo consultados, que a chegada ao Novo Continente foi o fruto de um complexo sistema de cálculos e de um atento exame da cosmografia das mais diversas épocas. Afirmou que, de um lado, os conhecimentos técnico-científicos em âmbito náutico, em particular aqueles contemporâneos a Cristóvão Colombo e a Paolo del Pozzo Toscanelli, favoreceram a realização de numerosas expedições marítimas; por outro lado, as explorações que seguiram lançaram bases para uma geografia física mesmo que aproximativa; o próprio Colombo, profundo conhecedor de cosmógrafos oficiais clássicos e medievais, habituou-se a descrever as margens onde praticava a cabotagem costeira e anotar as suas observações em textos de vários gêneros que chegaram até nós (Humboldt, 1836-39).

Em seguida, enquanto os primeiros Conquistadores se moviam no interior do Novo Continente na procura afanosa das fabulosas riquezas do Eldorado, surgiram outros interesses de caráter mais propriamente científico, documentados nas primeiras e esporádicas tentativas de produzir textos geográficos, como a Summa de Geografia di Fernández de Enciso de $1519^{1}$, textos por todos desprezados. Nos séculos sucessivos, após a colonização do território por parte dos espanhóis, quase todos os cronistas, nos seus escritos, comentaram notícias sobre

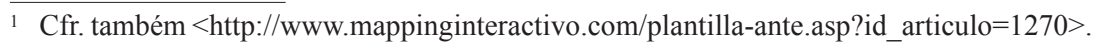


as viagens realizadas. Mas somente no início do século XIX foram iniciadas as primeiras campanhas de reconhecimento, relacionadas a projetos específicos, frequentemente motivados pelas pesquisas de gênero naturalístico, ultrapassando aquelas estritamente cartográficas. Foi apenas neste período que a inspeção do território se intensificou à procura de potencialidades, com vistas a um futuro desenvolvimento. Tal ação significava muito mais do que insistir na espoliação de riquezas, como consequência de uma vontade política e administrativa ditada por instâncias autônomas, reivindicadas pelas novas Nações.

Uma das tarefas dos novos governantes foi então aquela de definir os limites territoriais, empreitada que se revelou subitamente muito mais complexa, também por causa do território impenetrável e de fato inexplorado, mas rico em recursos naturais. Por isso, o interesse cartográfico sobrevém apenas no período neo-republicano, quando a Comissão Corográfica organizou uma ampla pesquisa científica patrocinada pelos Governos. Um dos protagonistas das primeiras viagens de reconhecimento e medições na parte setentrional da América do Sul, comissionados oficialmente, foi Agustín Codazzi, personalidade quase desconhecida na Itália, considerado heroi nacional na Venezuela, sepultado no Pantheon de Caracas onde são recordados todos os grandes herois do país, celebrado como el hombre de las tres patrias ${ }^{2}$.

\section{Vida e obra de Codazzi}

Gian Battista Agostino Codazzi ${ }^{3}$ nasceu em 12 de julho de 1793 em Lugo di Romagna, uma cidade clerical, parte do Estado da Igreja desde 1598. Descendia de família pertencente a uma das principais irmandades religiosas, que foi totalmente arruinada depois do "saque" operado pelas tropas napoleônicas em 1796, porque a cidade resistira através de uma revolta antifrancesa. Napoleão impôs a conversão dos institutos religiosos em escolas militares, segundo o modelo francês e, também na Romagna, a mentalidade reacionária e conservadora foi sendo lentamente substituída por novas ideias mais liberais. Também Agostino orientou-se em direção à carreira militar, seja pela falta de recursos necessários para dar continuidade aos estudos de advocacia,

2 Na América Latina, outros Institutos geográficos nacionais da Venezuela e da Colômbia, dedicam a ele também numerosas escolas, estradas e monumentos.

3 Fonte principais: Lessona, 1869. <http://www.treccani.it/enciclopedia/agostino-codazzi (Dizionario-Biografico)/>; $<$ http://www.codazzi.mitreum.net/it/prefazione.php $>$ conteudos do Prof. Giorgio Antei. 
tão desejados por seu pai, seja pelo desejo de viagens e aventuras que a carreira militar poderia proporcionar. Assim, a frequência na Escola Militar em Bologna e, posteriormente, em Pavia, na Escola Teórico Prática de Artilharia, emanação da École nationale des ponts et chaussées francesa, revelaram-se de fundamental importância às suas futuras atividades (Zucca, 1898).

Alistado com apenas vinte anos de idade entre as fileiras do exército napoleônico, participou de diversas batalhas até que, depois da dispensa e não encontrando possibilidade de trabalho no âmbito militar, empreendeu a atividade comercial que o levou a viajar para numerosos Estados do leste europeu, continental e mediterrâneo. Enfim, não resistindo mais aos chamados da vida militar, da Holanda escreve ao pai declarando a vontade "de pegar em armas a cada sinal, pela defesa do Estado. [...] ou verdadeiramente unir-me aos bandos de rebeldes Americanos Espanhóis." 4

Junto com o conterrâneo Costante Ferrari, acabou embarcando para a América do Sul, onde participou ativamente da formação dos novos Estados da Colômbia e Venezuela, oferecendo os seus serviços ao futuro Libertador Simon Bolívar. Depois de um breve e decepcionante retorno à Itália, entre 1823 e 1826, voltou definitivamente para a América do Sul, onde recebeu das Autoridades locais novos encargos militares, sobretudo de caráter geográfico, como o levantamento topográfico e corográfico da região Zulia, com o objetivos iniciais quase exclusivamente estratégicos e táticos. Sucessivamente, depois de tê-lo nomeado Chefe do estado maior, foi o próprio presidente da Venezuela, José Antonio Páez, a encarregá-lo da redação de um relatório estatístico sobre o País e um Atlas sobre as suas treze Províncias. Dedicou-se a essas atividades de 1831 a 1839, realizando uma longa série de explorações. Escreve Trinca Figuera: "Hasta la publicación de su obra, el territorio de la República de Venezuela, geográficamente hablando, se presentaba a una escala que no permitía aproximaciones en detalle de las provincias que, para ese entonces, tenía el país. El trabajo de Codazzi subsana este problema, ya que tanto su Geografia de Venezuela como el Atlas, permiten tener una visión de conjunto del país no conocida hasta ese momento" (Trinca Giguera, 2000, p. 5-7).

Além disso, entre as incumbências importantes que lhe foram confiadas a respeito do exército sul-americano, coube a Codazzi

4 “Olanda, Amsterdam, li 28 Aprile 1817” < http://www.codazzi.mitreum.net/it/biografia/ viaggiobalcani.php>. 
a delicadíssima questão, em nível diplomático, de traçar as linhas fronteiriças ${ }^{5}$ entre Equador, Colômbia e Venezuela. Assume a nacionalidade venezuelana no dia seguinte à dissolução da Grande Colômbia, quando termina o sonho bolivariano de criar o Estado Pan-americano. A finalidade prioritária era aquela de dar, através da definição topográfica do território, uma identidade a nova-nação ${ }^{6}$, além de que "herramienta esencial para el ejercicio de gobierno nacional de esos años" , tarefa que Codazzi assumiu com grande profissionalismo ${ }^{8}$ e um rigor científico reconhecidos por todos, incluindo Humboldt que lhe escreveu uma carta de próprio punho9. Também foi prestigiado pela Academia das

5 Observo a problemática da definição das fronteiras no final do século XVIII. cfr. O aprofundamento a nota 17 p. 66-7, in Costa, (2006, p. 62-92).

6 "Para a Venezuela -declarou no Congresso com o ato de aprovar a proposta de Páez (14 de outobro de 1830)- o levantamento topográfico das cartas geográficas, a determinação dos percursos militares e a elaboração de informações estatísticas é um empreendimento de urgente necessidade, cujos resultados terão efeitos benéficos sobre a execução das operações militares, sobre o conhecimento das fronteiras provinciais, sobre uma distribuição mais igual dos impostos, sobre o desenvolvimento da agricultura; para não falar da abertura e a construção de novas vias de comunicação, para a melhoria dos pântanos e da navegação fluvial". <http://www.codazzi.mitreum.net/it/biografia/spadateodolito.php $>$.

7 <http://www.scielo.org.ve/scielo.php?pid=S0254-16372007000200007\&script=sci_arttext $>$.

8 Estas são as palavras do próprio Codazzi pronunciadas durante a cerimônia de entrega:

"La tarea que el gobierno me encomendara hace ocho años ha sido terminada. Cada provincia de la república cuenta ahora con su mapa corográfico en escala grande; cada una es dueña de una clara información sobre todos sus cantones, de precisos datos sobre caminos militares, amén de copiosa información de orden geográfico, físico y estadístico.» $<$ http://www.codazzi.mitreum.net/it/biografia/impresacorografica.php>.

9 "Uma comissão composta por senhores de Arago, Savary, Elia de Beaumont e Boussingault, o examinou e lhe fez um contato com a Accademia, a qual decidiu que lhe escrevesse uma carta para Codazzi, significando-lhe que o seu trabalho geográfico-estatístico era tido como de grande propriedade. E o senhor Elia de Beaumont que havia esta função, então lhe escreveria: "Não posso manifestar o quanto me agradou e me ensinou obtive a partir da vossa obra. Mais a estudo, e mais me convenço que foi exata a opinião que os senhores de Arago, Savary, Boussingault e eu emitimos anteriormente para a Accademia. Os aplausos dos amadores das ciências, que vos devem muito, serão por vós uma grata recompensa. Mi permita entretanto apresentar-vos um pequeno tributo da minha admiração pelo saber, a costância ed o valor, que explicastes em um empreendimento assim vasto e difícil"; "Monsieur le Colonel, je ne puis vous voir pour ce beau pays qui m'à laysé de souvenirs si chers, sans vous renouveller l'expression de ma haute et affectuese consideration. Vos travaux géographiques embrassant une si immense étendue de pays, offrant à la fois de detail topographique le plus exacte et des mesures des hauteurs si importantes pour la distribution de climats, feront epoque dans l'histoire de la science. Il m'est doux d'avoir veçu assez longtemps pour voir en termine une vaste enterprise que, en illustrant le nom du Colonel Codazzi, contribue a la gloire du governement qui a eu la sagesse de le proteger. Ce que j'ai tenté de faire dans un voyage rapide, en jettant un reseau de positions astronomiques et hypsometriques sur le Venezuela et la Nouvelle-Grenade, à trouvé par vos nobles investigations, Monsieur, une confirmation et un agrandissement qui depassent mes ésperances. Membre de l'Academie des Sciences, j'aurai signé avec plaisir, si j'eusse eté en France, l'excellent rapport que deux de mes plus intimes amis, Mr. Arago 
Ciências e pela Sociedade Geográfica de Paris que o nomeou sócio e lhe conferiu a grande medalha com a legenda "a Sociedade de Geografia ao engenheiro Agostino Codazzi por suas explorações nas províncias da Venezuela". Fica assim qualificado como "engenheiro", omitindo o cargo militar, testemunhando o quanto foi considerado prioritariamente meritório o aspecto técnico-científico da sua obra, em detrimento daquele caráter bélico. Também a Real Sociedade de Geografia de Londres concedeu-lhe o diploma de membro correspondente, e a Sociedade Etnológica Americana, estabelecida em Nova Iorque, conferiu-lhe o título de membro honorário. O Rei Luís Felipe, aceitando a proposta do ministro Guizot, atribuiu-lhe a Ordem da Legion d'Onore", em 1842, com a seguinte motivação: "demonstração de particular benevolência do Rei diante de um antigo oficial de Estado Maior do Exército do Reino Itálico às ordens do Príncipe Eugenio".

$\mathrm{O}$ resultado tangível do trabalho de fichamento, mapeamento e descrição do território venezuelano efetuado por Codazzi, entre os anos 1830 e 1840 está reunido em algumas obras ${ }^{10}$ que ainda hoje são fundamentais ao conhecimento histórico e geográfico da América do Sul.

Em 1839, o Congresso Nacional aprovara os planos originais dos levantamentos de Codazzi e autorizara a publicação que ele dedicara à nova pátria. Codazzi viaja a Paris onde, entre 1840 e 1841, foram publicados o Resúmen de la Historia de Venezuela, l'Atlas fisico y político de la República de Venezuela, constituído de dezenove placas, com 30 mapas históricos, físicos e políticos, e o Resúmen de la Geografía de Venezuela, em formato descritivo, sub-dividido em três partes (geografia física, geografia política e descrição das treze províncias venezuelanas) e acompanhado de placas demonstrativas e comparativas.

Em síntese, na biografia de Codazzi destacam-se dois aspectos que marcaram profundamente as suas escolhas de vida: em primeiro lugar a formação nas duas escolas militares que lhe forneceu conhecimentos teóricos e técnico-práticos, sem as quais não lhe seria possível afrontar

et Boussingault on fait sur votre Carte et sur les ouvrages historiques e géographiques destinez a l'illustrer [...] Paris, ce 20 Juin 1841 Alexander Humboldt». Testi originali tratti da Lessona, Michele (1869).

10 Para ver o elenco completo $\mathrm{cfr}$. $<\mathrm{http}$ ://www.treccani.it/enciclopedia/agostino-codazzi (Dizionario-Biografico)/>. Per l'Atlas cfr. <http://www.cervantesvirtual.com/obra/atlasfisico-y-politico-de-la-republica-de-venezuela--0/>. Cfr. anche $<\mathrm{http}$ :/www.geographos. com/BLOGRAPHOS/?p=306> para ler o prólogo escrito por Codazzi. 
os empreendimentos cartográficos na América do Sul durante quase toda a sua existência. Em segundo lugar, a atividade militar foi iniciada pelos ideais que sempre lhe sustentaram e que foram demonstrados na participação das lutas com Napoleão pela realização dos princípios da Revolução Francesa e, posterirmente na América, pela independência do domínio colonial espanhol e pela afirmação das soberanias nacionais. Sucessivamente, ver-se-á em que medida a atividade de geógrafo satisfez a sua grande sede de conhecimento e de sistematização do mundo novo conhecido, segundo os princípios do iluminismo e do positivismo de sua época. No caso do iluminismo, Codazzi acabou influenciado pelos aspectos mais revolucionários de luta anti-aristocrática, à luz daqueles valores de liberdade, igualdade, direitos humanos e laicidade do Estado; o positivismo inspirou seu entusiasmo pela difusão do progresso graças às diversas aplicações tecnológicas que foram possíveis somente através do emprego de uma rigorosa metodologia científica. As explorações no território foram por ele conduzidas pessoalmente, observando e medindo, mas também comentando de maneira subjetiva, e depois confrontado com os dados de outros estudiosos, fossem anteriores ou contemporâneos. Animado por estes princípios, Codazzi trabalhará durante toda a sua vida, de maneira coerente e adequada aos ideais juvenis aos quais não renunciou jamais $^{11}$.

\section{Do mito a realidade, da realidade a utopia}

De Codazzi já muito foi dito escrito, sobretudo na América Latina, por estudiosos de várias áreas, confirmando a multidisciplinaridade da obra codazziana ${ }^{12}$ Mas a leitura integral do Resúmen de Geografia de Venezuela, com específica atenção à parte física e com o olhar

11 Nos anos sucessivos, transferindo-se para a Colômbia por causa das revoluções políticas venezuelanas, lhe foi confiada a função de terminar um Atlas físico e político da Nova Granada, tarefa para desenvolver no interior da Comisión Corográfica oficialmente constituída pelo Governo e composta por diversos especialistas. Mas foi o próprio durante a enésima viagem ao território dos Andes colombianos que havendo contraído a malária, encontrou a morte em 7 de fevereiro de 1859 no Espiritu Santu, hoje em dia por todos chamada de "Aldea Codazzi". <http://www.codazzi.mitreum.net/it/biografia/peraspera. php>. No mesmo ano morreu também Humboldt.

12 Importantes na Itália os estudos do historiador italiano, Fabio Zucca, relativamente sobre a formação inicial, sobretudo aquela militar, do nosso, enquanto, entre os demais, se podem citar seja a Tese de doutorado do historiador da Arquitetura, Juan José Peres Rangel, seja a monografia do diplomata alemão na Colômbia, Hermann Albert Schumacher (1839-1890), o seu primeiro biógrafo crítico. 
constantemente dirigido as suas obras precedentes, constitui ainda hoje ma rica fonte para interpretações ${ }^{13}$.

Em primeiro lugar, a consulta do Resúmen, que constitui o anexo descritivo do Atlas, auxilia o leitor a medir a adequada preparação técnica, científica e instrumental de Codazzi para desempenhar as tarefas que lhe foram confiadas, mas sobretudo a sua vasta cultura, profunda consciência dos protagonistas de análogas explorações nas diversas épocas, assim como das suas teorias e, em última análise, dos textos por eles escritos. As citações em mérito são numerosas. O seu comportamento é sempre aquele do confronto aberto e ditado pela curiosidade científica, muito mais que inquisitivo ou tanto menos desprezador. Lembra-se o episódio do encontro com Tyrrel Moore, um engenheiro inglês que vivia em Medellín que, "com uma paciência digna do maior louvor, por força de triangulações, estabeleceu a posição geográfica em mais de 50 países”. Continua Codazzi:

[Moore] tinha uma grande vontade de conhecer os meus resultados, a fim de colocá-los em confronto com os seus [...] De outro lado, eu também desejava ardentemente comparar os meus levantamentos com aqueles de um homem especialista na matéria, uma possibilidade que não me foi nunca apresentada quando trabalhei na América. ${ }^{14}$

$\mathrm{Na}$ Advertencia inicial vêm citadas as fontes consideradas mais influentes. Pela classificação dos vegetais, a obra de Ramón de la Sagra; para aquela dos animais, Roulin e Berthelot além do Museu Mexicano; para a Geografia Política, os escritos de Humboldt, que permanece como o mais citado em toda obra, Depons e o atlas etnográfico de Balbi. Quanto a outros autores levados em consideração, se somente considerados aqueles mencionados no curso do estudo, como por exemplo, Schomburgk, explorador alemão a serviço dos ingleses, são muito mais numerosos e também por outros não diretamente nominados. Quase seguramente conhece os textos, como no caso do

${ }^{13}$ Foram consultados seja o original em castelhano seja a edição italiana do Resúmen organizado por G. Foschini, Geografia statistica di Venezuela, Firenze, Bettini, 1864. A tradução, bastante fiel pelo estilo do mesmo período, resulta fortemente reduzida na parte relativa as províncias. O Índice geral da versão em castelhano é de fato então composto: Geografia fisica 1-237; Geografia politica 238-352; Geografia de las provincias 353-640, enquanto aquele da versão italiana resulta o seguinte: Geografia fisica 2-312; Geografia politica 313-432; Geografia de las provincias 433-464. As citações em nota assinalam seja as páginas de referência da versão castelhana seja as da italiana. Doravante a referencia será: Foschini, 1864, Cast. p. 90-1; It p. 136-38.

$14<$ http://www.codazzi.mitreum.net/it/biografia/progressi.php $>$. 
livro de Geografia Moderna, de Giuseppe Pagnozzi (1823), talvez o mais completo da época, do qual recupera alguns dados. As referências e pareceres sobre os demais autores são frequentes:

Os antigos viajantes escassamente instruídos nas ciências naturais, pouco se aplicaram nas pesquisas botânicas e geológicas; investigaram porém os minerais, mas dos quais, por não acreditarem na abundância dos minerais nesse país, não nos permaneceu nenhuma referência exata. Sem os cansativos estudos de alguns estudiosos estrangeiros que em épocas muito recentes visitaram os países equinociais, naquele lugar guiados por seu amor pelas ciências, (refere-se seguramente a Humboldt e Bonpland) a Venezuela ficaria desconhecida na Europa como são as regiões mais remotas da Oceania ou da África, embora em nenhum momento faltassem exploradores espanhóis suficientemente hábeis para dar conhecimento do país em todos os seus aspectos. O jesuíta Acosta, por exemplo, na sua História Natural e Moral dos Índios [...] Esta obra porém não é um tratado científico, e está bem distante de satisfazer os especialistas, que hoje a consultam mais por curiosidade que para extrair alguma utilidade. Nos tempos que seguiram, D.Jorge Juan e D.Antonio Ulloa, fizeram, por ordem do governo Espanhol, uma viagem para a América [...] mas nem tiveram tempo, nem foi seu propósito principal a ciência. Esses foram muito mais mandados como inquisidores políticos, que exploradores da natureza; [...] Além disso, nenhum destes beneméritos espanhóis visitou tampouco o território venezuelano. A pobreza proverbial destes lugares em relação aos minerais, fazia que o governo espanhol voltasse sua atenção sobre as ricas possessões do México e Peru. Verdade tanto certa e geral, que somente não é aplicável às ciências naturais, mas aos trabalhadores puramente geográficos, que talvez exigem menor tempo e menores recursos para a sua execução. Excetuam-se algumas cartas hidrográficas, feitas nos últimos tempos por Fidalgo e Churruca; não existe nenhum trabalho desse gênero, pelo menos conhecido, que fosse ordenado pelo governo espanhol; não existe depois nenhuma outra obra corográfica. (Foschini, 1864, Cast. p. 90-1; It p. 136-38 it).

De forma similar, Codazzi distancia-se dos boatos fantasiosos sobre o outro lado do oceano, recorrentes em alguns ambientes europeus, como aqueles dos Missionários que, "acreditando nas narrativas dos indígenas, inventavam a nação dos Rayas, homens que tinham a boca no umbigo. E do mesmo modo [...] os próprios religiosos localizavam os povos que haviam um olho no meio da testa e outros com a cabeça de cão" (Foschini, 1864, Cast. p. 74.; It. p. 136). 
Ao contrário, Codazzi mantém uma perspectiva estritamente científica. Segundo ele, a passagem do mito à realidade pode verificarse apenas através da ciência: "Esse grande sistema de vales, originando rios de muita água, causou a crença que existisse no centro desta planície uma cordilheira [...] enquanto na realidade não existia nada, se não uma grande planície" (Foschini, 1864, Cast. p. 18; It p. 27).

Codazzi aponta em diversas partes da sua obra algumas das etapas mais importantes na pesquisa do Eldorado na Venezuela, sublinhando ao mesmo tempo o insucesso. Lembra então as expedições de Ordaz, Herrera, Spira e Raleigh, assim como a procura do império fabuloso do Gran Patitì, na Bolívia. O tom é às vezes irônico, sobretudo quando coloca em evidência a perspicácia dos indígenas em afastar os ingênuos e ávidos Conquistadores europeus ${ }^{15}$.

Nos sucessivos confrontos com os habitantes nutre sentimentos contrastantes; às vezes se lança contra os colonizadores europeus e os missionários, exaltando o valor dos indígenas em luta pela sua autonomia:

Montanhas desertas cobrem aquele espaço habitado nas margens de rios pela feroz tribo dos Guaicas e outros, que também não esquecem a perseguição dos espanhóis, quando estes, unidos aos holandeses, se internavam naquele lugar roubando Índios para fazê-los escravos [...]. Nas margens dos rios encontram-se homens ferozes de diferentes tribos, que interromperam os frades missionários nas suas sistemáticas perseguições aos naturais da terra. Encontram-se errantes nas planícies, entre as montanhas Roraima e Rinocote [...] algumas tribos valorosas que souberam defender a sua independência [...] As margens do Caronì [...] apresentam quedas d'águas perigosas; mas estes obstáculos não foram suficiente barreira contra as expedições dos frades capuchinhos que se apossavam, de surpresa e com de armas em punho, dos índios Achivagotos, Baringotos e Armacotos, cujos vestígios existem ainda. (Foschini, 1864, Cast. p. 73-74; It. p. 115).

Em algumas ocasiões foi reconhecido o mérito dos europeus, por terem trazido progresso e cultura filosófica:

\footnotetext{
15 "Nestes bosques imensos, os intrépidos conquistadores procuravam o império fantasioso do Gran Patitì, [...] Quimera lisonjeada que os indígenas sabiam alimentar para se desfazer de seus incômodos hóspedes, empurrando-os então sempre mais ao interior, na procura daquilo que não existia. Era um fantasma que constantemente haviam em vista sem podê-lo encontrar." Foschini, 1864 Cast. p. 75; It p. 114.
} 
Habitavam estas ilhas (Antilhas), antes da conquista, numerosas tribos selvagens, sem indústria alguma, sem culto e quase sem folclore; hoje porém encontram-se povoadas de indivíduos de diferentes nações europeias que levaram o cristianismo, as ciências, a agricultura e outras artes; várias coisas que transformaram os desertos em belas cidades, em campos bem trabalhados, e aqueles mares são vivos de comércio, enquanto eram singrados somente pelas pirogas dos antropófagos do Caribe. Quando a Espanha administrava avidamente as colônias a fim de mantê-las sem comunicação com o resto da Europa, quando a nenhum estrangeiro era permitido penetrar e nem mesmo alcançar aquelas terras, das quais apenas se conhecia a existência pelo ouro das suas minas. A Venezuela deve muito às populações estabelecidas nas ilhas, recebendo a influência e o impulso de uma civilização mais avançada. Convertidas aquelas ilhas em fazendas das nações mais industriosas e mais desenvolvidas do velho continente, a Europa era como se fosse próxima da costa da terra firme, e transmitia facilmente, com seus preciosos objetos de arte, o produto mais precioso das suas luzes e da sua filosofia. (Foschini, 1864, Cast. p. 45; It. p. 70).

Em resposta à aura mítica que há sobre o território venezuelano, Codazzi emite seu severo parecer. O cientista contrapõe a observação e o exame a respeito do país; na seção dedicada aos minerais escreve:

embora a Venezuela pertença à região equinocial, considerada geralmente como a pátria do ouro e da prata, não se conhecem as ricas minas destes preciosos metais [...] No tempo da conquista, na metade do século XVI, fizeram-se tentativas do Capo da Paria até aquele da Vela, ingressando no país inteiro para investigar de onde vinha aquele metal precioso, encontrado pelos primeiros navegadores entre os habitantes da costa, e do qual se adornavam. Se soube assim de Coro, Curiana e Caucheto, que aquele ouro vinha da serra de Cundinamarca - Colômbia; mas contrariamente a tudo isso, o território da Venezuela viu-se explorado com ganância. (Foschini, 1864, Cast. p. 151; It. p. 209-10).

Codazzi assume assim posição contrária à exploração do subsolo posto em prática sem escrúpulos, engajando-se a favor do planejamento e regulamentação do cultivo dos terrenos. Prossegue:

nestes últimos tempos encontrou-se uma mina de prata em Bailadores, província de Mérida, sem contar muitos outros pontos nos quais se acharam algumas piritas e palhetas de ouro; tudo isso, porém não prova absolutamente que aquele país contenha minas de 
semelhantes metais, bastante ricas para serem trabalhadas, ficando o problema se, com o tempo, os seus habitantes desfrutarão do fulgor transitório que dão as minas. É mais provável que, vendose amplamente indenizados, seguirão as produções preciosas e inextinguíveis de um solo que, em razão da sua fertilidade e extensão, será a residência da felicidade; [...] (Foschini, 1864, Cast. p. 152; It. p. 212).

Estas últimas avaliações abrem o espaço para a reflexão sobre o Codazzi utopista. As suas observações sobre o território, por outro lado, mesmo que mantendo uma rigorosa formulação científica - "observamos", "examinamos" - não são neutras mas, ao contrário, fazem perceber um forte sentimento idealístico. A Venezuela sai retratada como uma espécie de Paraíso terrestre. Na descrição do território insiste, sobretudo, sobre as suas potencialidades. Em se tratando das costas e portos:

'O extenso golfo de Cariaco, pode ser considerado como um grande e protegido porto, capaz de conter todas as frotas reunidas da Europa [...] De nenhum valor é o dano que atualmente sofre o país, na proporção de grandes vantagens que receberá no futuro [...]' (Foschini, 1864, Cast. p. 48; It. p. 75-6), de lagos e lagunas, como aquele de 'Maracaibo [...] pelas imensas florestas que o circundam; as quais se apresentam ao homem agricultor com todas as vantagens de uma terra fértil e virgem.' (Foschini, 1864, Cast. p. 40; It. p. 61).

Detém-se analisando terrenos cultiváveis, como se verá mais adiante. Codazzi se esforça para oferecer ao leitor um quadro o mais realístico possível daquilo que considera então o luminoso porvir do seu novo País, chamando em defesa da veridicidade das suas hipóteses o parecer de outros europeus, como o agente do governo francês em Caracas, Depons, o qual

[...] não há duvida em sustentar que, em nenhuma parte da América, em qualquer latitude se seja, não se pode comparar a esta fertilidade, variedade e riqueza. Efetivamente assim ocorre, e para bem apreciar isto, é necessário observar sob o aspecto do futuro. Não queremos apresentar quadros ideais, concebidos por imaginações transviadas pela força do entusiasmo: nem infundir quimeras impossíveis. Procuraremos sem dúvida acenar os avanços que estão na ordem dos progressos humanos: os melhoramentos que se devem esperar de uma população crescente num país que possui grandes vantagens naturais: as modificações exatas que receberá a terra por meio da civilização e da cultura. (Foschini, 1864, Cast. p. 50; It. p. 78). 
Apesar desta afirmação inicial, não se pode evitar de observar como o entusiasmo do neo-venezuelano é amplo e difuso em grande parte do texto, pois apresenta trechos de verdadeira exaltação, quase mística, se com isso se entende o estupor, mas também a admiração por aquilo de transcendente que pode haver no universo em geral. Ambos nascem da contemplação da grandiosidade da paisagem, quase infinita e, ao mesmo tempo, do respeito pelo que foi criado: "Terras felizes, cheias de esperanças, onde Deus criou suaves e agradáveis ventos e águas, o céu puro e sereno, campo fecundo, costumes afáveis e hospitaleiros." Os mesmos sentimentos nutre também Humboldt, cujas palavras emprega quando conclui o parágrafo de introdução sobre o Aspecto físico do País, assim comentados por Codazzi: "Rápido, verdadeiro e belo quadro traçado pela mão mestra; [...] impressões profundas e singulares que representam para a mente o maravilhoso da criação primitiva em uma pureza original" (Foschini, 1864, Cast. p. 49 ss; It. p. 76 ss). Os dois geógrafos insistem seguidamente sobre o fator "natura incontaminada", isto é, ainda não tocada pelo homem, mas isto serve para demonstrar como o próprio homem pode e, num certo senso, deve intervir para alcançar o resultado - não explorar- as potencialidades de tanta riqueza. Em síntese, o pensamento global que transparece é o seguinte: Venezuela é fértil e rica de matérias-primas, tem um clima ideal e abundância de águas, quer dizer, é potencialmente muito próspera; basta que o homem intervenha e o resultado será incomensurável. O uso frequente na escrita, do tempo hipotético e do futuro, contribui para colocar ainda mais em relevo a sensação de confiança sem limites nas qualidades da paisagem venezuelana, assim como nas capacidades quase onipotentes do homem na sua iniciativa transformadora sobre a natureza, convenção também essa compartilhada com Humboldt, que afirma:

não se acredita que os efeitos do clima úmido e, em algumas partes, insalubre, numa atmosfera cheia de insetos, possa colocar obstáculos aos progressos de cultivo nas selvas da Guayana: esperamos que o homem, como aconteceu em todas as partes e em todos os tempos, mudando a superfície do solo, mudando também a constituição da atmosfera, e os insetos terminarão bem rápido, quando desaparecerem as velhas árvores dos montes, e quando nestas regiões veja-se os rios povoados de cidades e vilarejos, e as planícies cultivadas, cobertas de casas e fazendas. (Foschini, 1864, Cast. p. 78-9; It. p. 124).

E Humboldt ainda acrescenta: 
As montanhas da península de Paria são quase desertas. É pouco o terreno cultivado mas, quando tudo for trabalhado, cada fazenda terá a vantagem de embarcar em seu território os seus produtos [...] Quando essas selvas forem transformadas em fazendas e se cultivarem $[\ldots]$ quantas múltiplas produções não sairiam destes terrenos, tanto beneficiados pelo clima, pela generosidade da terra e pela fácil exportação por água! [...] os terrenos pantanosos transformados em terras aradas encerrariam cidades ricas e comerciais. (Foschini, 1864, Cast. p. 55-6; It. p. 87-9).

Codazzi insiste com frequência nos binômios deserto versus habitável, incultivável versus cultivável, lugares inabitáveis versus infra-estrutura. Quer dizer cidades, portos, estradas, sempre usando o futuro:

virá um tempo em que [...]. Observa-se que apenas algumas fazendas costeiam o lago; que nestas costas encontram-se poucas populações sem nenhuma importância e que, no remanescente sempre selvagem do país, a árvore do cacau encontra-se inteiramente inculta. Se terá notícia do que Maracaibo deverá ser nos tempos futuros, quando uma população ativa e proporcional ao seu tamanho saiba tirar partido de todos as suas vantagens. (Foschini, 1864, Cast. p. 57ss ; It. p. 90-92; 94).

Expressões deste tom e gênero são recorrentes ao longo de todo o texto, em relação a quase todas as 13 províncias venezuelanas. Para tornar ainda mais verídicas as suas afirmações chega a apresentar cálculos comparativos entre a extensão e a população, concluindo que são cálculos corretos: "Os seguintes quadros darão a demonstração". O modelo de referência para os seus argumentos é naturalmente aquele europeu, por ele bem conhecido em virtude das viagens realizadas na juventude: "Talvez estes pântanos e terrenos submersos, nos quais os naturais são obrigados a viver sobre as árvores, serão um dia, ao modo dos terrenos cultivados na Holanda, o empório da agricultura e do comércio" (Foschini, 1864, Cast. p. 48; It. p. 74). A este ponto é lícito queres saber sobre quais seriam os homens protagonistas da mudança. Codazzi responde também a esta interrogação: "Quando as emigrações e as gerações futuras começarem a derrubar as grandes selvas e o interesse mercantil chamar os novos colonos, então estas solidões mudarão de aspecto, pois o homem branco tem apenas percorrido os rios principais" (Foschini, 1864, Cast. p. 78-9; It. p. 124). 


\section{Conclusão}

Pelo exposto, pode-se individualizar dois aspectos interpretativos, particularmente dignos de nota na reflexão sobre Codazzi: a perspectiva humanista e aquela utópica.

A presença no texto de numerosos esquemas sintetizadores e tabelas, como aquelas sobre a queda das águas e subsequentes placas climatológicas, aquela dos terrenos cultivados em relação às terras virgens, ou ainda o quadro da "população geral da Venezuela para conhecer o seu crescimento, incluídos os indígenas independentes" (Foschini, 1864, Cast. p. 244; It. p. 317), demonstram o imenso esforço de catalogação dos aspectos propriamente físicos, mas também antrópicos de uma Venezuela ainda quase desconhecida. Codazzi usa técnicas de abordagem atuais no território, não apenas cientificamente adequadas ao relevo cartográfico ${ }^{16}$, mas também pela multidisciplinaridade que caracterizam.

Mas há mais. Se Codazzi deve ser justamente incluído, junto a outros poucos da sua época, como Humboldt ${ }^{17}$, entre os primeiros geógrafos modernos, para ele se pode também avançar com a definição de geógrafo "humano" e, como tal, precursor da geografia humanística inaugurada por Vidal de La Blache (1845-1918), pouco posterior a ele. Este geógrafo francês, fundador da revista Annales de Géographie (1891), que se contrapõe ao determinismo geográfico então corrente, capaz de ver o homem como impotente diante da tirania da Natureza, crê firmemente que a humanidade possa intervir sobre o território, modificando-o ao seu favor, graças ao progresso tecnológico e aos implícitos avanços culturais.

Como está exposto, Codazzi prenuncia mudanças para o território venezuelano. Pode-se, portanto, formular a hipótese de que essa não é uma filiação casual à nova orientação de pesquisas no campo geográfico, visto que Codazzi esteve ligado à cultura francesa contemporânea. Não por acaso, foi filho da cultura italiana, francesa e, indiretamente, também da alemã. Enfim, um homem europeu ante litteram, que colocou-se o seu saber a serviço dos recentes Estados latino-americanos mas, sobretudo, o seu saber fazer relacionado à paixão e à dedicação para com sua nova terra de adoção.

16 "The work of Codazzi was an invaluable accomplishment according to the scientific standards of his time and provided the government of the new nation with most necessary first-hand data and maps of the territory" Caballero (1994).

${ }^{17}$ Mais recentemente foram avançadas sobre as críticas sobre a real "modernidade" do método geográfico de Humboldt. Cfr. Escamilla Vera (2001). 
Uma última reflexão se refere à forte tendência utopística do pensamento codazziano. Se de fato Codazzi parte de determinada crítica à concepção mítica, enquanto tal ligada ao passado que envolve a terra venezuelana, para depois vir a reapresentá-la no presente como descrição da realidade atual, é verdade também que o próprio Codazzi, partindo desta segunda visão, destaca-se por projetar à uma concepção fortemente utópica, quando volta o seu olhar cheio de admiração ao futuro da recém-nascida Venezuela, novo Eden na terra. Como na literatura utopística a ele contemporânea lê-se da aspiração a um mundo onde reinam incontestes princípios de justiça e de igualdade entre os homens, com o retorno a uma felicidade originária. Suas próprias veleidades ocorrem muitas vezes tanto nos escritos, como é apenas sublinhado, como na vida real do nosso protagonista. Em sua permanência na Itália, entre 1823 e 1826, encaminhou um experimento vanguardista ${ }^{18}$ como empreendedor agrícola, falido miseravelmente por uma série de problemas financeiros. Êxitos alternativos obteve o projeto da fundação da Colônia de $\operatorname{Tovar}^{19}$, encaminhado em 1843, apoiado pelo próprio Humboldt e aprovado no Congresso Nacional, prevendo a colonização de um pequeno território determinado por Codazzi no interior das elevações costeiras da Venezuela, através de emigrantes alemães ${ }^{20}$. Por estas últimas iniciativas, emerge a figura de um homem que, mesmo tendo transcorrido a sua vida sob rígidos protocolos militares e científicos, permaneceu sempre um grande sonhador, destemido idealista e defensor dos valores mais altos da humanidade.

\section{Referências}

CABALLERO, Beatriz, Las Siete Vidas de Agustín Codazzi. Bogotá, Instituto Geográfico Agustín Codazzi, 1994.

COSTA, Giorgio, Viaggio alle regioni equinoziali del Nuovo Continente fatto negli anni 1799, 1800, 1801, 1802, 1803 e 1804 da Alexander von Humboldt e Aimé Bonpland Relazione storica. Tomo I, II, III, in Quaderni della Ri-Vista, anno 2, v. 1, n. 2, gennaioaprile 2006, p. 62-92.

${ }_{18}$ A Massalombarda <http://www.codazzi.mitreum.net/it/biografia/interludioromagnolo.php $>$.

19 Tovar era o nome do proprietário dos terrenos cedidos pela colonização <http://www. codazzi.mitreum.net/it/biografia/coloniatovar.php>.

${ }^{20}$ Deste aspecto particular se ocupou de maneira crítica e aprofundada Perez Rangel no segundo e terceiro capítulo da sua tese de dotorado: Agustín Codazzi y la construcción del Nuevo Mundo, Caracas, Petroglifo Producciones, 2002. Cfr. também a crítica de A.Arellano Cárdenas <http://www.scielo.org.ve/scielo.php?pid=S0254$16372007000200007 \&$ script $=$ sci_arttext $>$. 
ESCAMILLA VERA, Francisco. Apuntes críticos sobre la obra geográfica de Alejandro de Humboldt, in Revista Bibliográfica de Geografía y Ciencias Sociales, v. VI, n. 324, 20-11-2001.

FOSCHINI, G. (Org.). Resúmen, Geografia statistica di Venezuela. Firenze: Bettini, 1864. HUMBOLDT. A. von. Histoire de la géographie du Nouveau Continent et des progrès de l'astronomie nautique aux XV et XVI siècles comprenant L'histoire de la découverte de l'Amerique. Parigi: Gide, [1836-39].

LESSONA, Michele. Volere è potere. Firenze: G. Barbera, 1869.

PAGNOZZI, G. R. Geografia Moderna Universale ovvero descrizione fisica, statistica, topografica di tutti i paesi conosciuti della terra. Firenze: Casa Editrice Vincenzo Batelli, 1823.

TRINCA FIGHERA, Delfina. Un geógrafo en Venezuela: Agustín Codazzi. Rev. Geog. Venez., v. 41, n. 1, 2000.

ZUCCA, Fabio. Agostino Codazzi e la scolarità a Lugo all'inizio del XIX secolo. In: Romagna Arte e Storia, n. 27, 1989.

ZUCCA, Fabio. La Scuola teoretico pratica di artiglieria di Pavia e la formazione di Agostino Codazzi (1810-1813). In: Bollettino della Società Pavese di Storia Patria, anno LXXXIX, v. XLI, n.s., 1989.

\section{Sites:}

ANTEI, Giorgio. < http://www.treccani.it/enciclopedia/agostino-codazzi_(DizionarioBiografico)/>. Acesso em: 10 jul. 2012.

ANTEI, Giorgio. <http://www.codazzi.mitreum.net/it/prefazione.php>. Acesso em: 10 jul. 2012.

$<$ http://www.codazzi.mitreum.net/it/biografia/impresacorografica.php $>$. Acesso em: 10 jul. 2012.

$<$ http://www.codazzi.mitreum.net/it/biografia/peraspera.php>. Acesso em: 10 jul. 2012.

$<$ http://www.codazzi.mitreum.net/it/biografia/progressi.php>. Acesso em: 10 jul. 2012. $<$ http://www.codazzi.mitreum.net/it/biografia/spadateodolito.php $>$. Acesso em: 10/ jul. 2012.

$<$ http://www.geographos.com/BLOGRAPHOS/?p=306>. Acesso em: 10 jul. 2012.

$<\mathrm{http}$ :/www.mappinginteractivo.com/plantilla-ante.asp?id_articulo=1270 > . Acesso em: 10 jul. 2012.

$<$ http://www.scielo.org.ve/scielo.php?pid=S0254-16372007000200007\&script $=$ sci_ arttext $>$.

$<$ http://www.treccani.it/enciclopedia/agostino-codazzi_(Dizionario-Biografico)/>. Acesso em: 10 jul. 2012.

Olanda, Amsterdam, li 28 Aprile 1817. <http://www.codazzi.mitreum.net/it/biografia/ viaggiobalcani.php>. Acesso em: 10 jul. 2012.

Per l'Atlas <http://www.cervantesvirtual.com/obra/atlas-fisico-y-politico-de-larepublica-de-venezuela--0/>. Acesso em: 10 jul. 2012. 